\title{
Aquaporin-1 Water Channel Protein in Lung Ontogeny, Steroid-Induced Expression, and Distribution in Rat
}

\author{
Landon S. King, ${ }^{\star \ddagger}$ Søren Nielsen, ${ }^{\S}$ and Peter Agre ${ }^{\star \|}$ \\ *Department of Medicine, ${ }^{\ddagger}$ Division of Pulmonary and Critical Care Medicine, ${ }^{\| D e p a r t m e n t ~ o f ~ B i o l o g i c a l ~ C h e m i s t r y, ~ J o h n s ~ H o p k i n s ~}$ \\ University School of Medicine, Baltimore, Maryland, 21205-2185; and ${ }^{\S}$ Department of Cell Biology, Institute of Anatomy, University of \\ Aarhus, DK 8000, Aarhus C, Denmark
}

\begin{abstract}
At birth water is rapidly reabsorbed from the distal lung in preparation for alveolar gas exchange. To investigate a potential role for the AQP1 water channel in development, lung membranes from fetal and perinatal rats were analyzed by immunoblot. First expression of AQP1 was noted in fetal rat lung at E19 (19th day of the 21-day gestation). The level of AQP1 increased fivefold from the last gestational day to the first postnatal day and persisted at high levels into adulthood. Maternal corticosteroids increased expression of AQP1 in fetal lung, an effect also seen in adult rats. AQP1 mRNA increased in rat pups treated with corticosteroids, suggesting at least partial regulation at the level of transcription. Immunohistochemical analyses with antiAQP1 demonstrated the protein in peribronchial vessels and visceral pleura at E21 with increased postnatal expression. AQP1 was not expressed in airway epithelium, and only occasional alveolar pneumocytes were labeled. Immunoelectron microscopy revealed AQP1 on both apical and basolateral membranes of endothelial cells. The ontogeny and corticosteroid induction of AQP1 in rat lung coincide with major physiological alterations in lung development; however, the distribution of AQP1 predicts the existence of other water channels in the alveolar epithelium. (J. Clin. Invest. 1996. 97:2183-2191.) Key words: edema • lung development • corticosteroids • bronchial circulation • pleura
\end{abstract}

\section{Introduction}

The lung undergoes a remarkable functional transition at the time of birth, and physiological aspects of perinatal lung fluid balance have been extensively studied. Fluid is secreted into the airways throughout much of gestation; lung fluid content is thought to be important for normal lung development (1). Near parturition, lung fluid secretion stops and accumulated water is reabsorbed from the airspaces as the lung prepares to

Portions of this work were presented at the American Thoracic Society meeting, May 22, 1995, and are published in abstract form (1995. Am. J. Resp. Crit. Care Med.151:A437).

Address correspondence to Peter Agre, Johns Hopkins University School of Medicine, 725 North Wolfe Street, Baltimore, MD 21205. FAX: 410-955-3149; E-mail: agre_lab@qmail.bs.jhu.edu; or Søren Nielsen, University of Aarhus, DK 8000, Aarhusc, Denmark. FAX: 45-86-198664; E-mail: sn@ana.aau.dk

Received for publication 25 September 1995 and accepted in revised form 26 February 1996.

J. Clin. Invest.

(C) The American Society for Clinical Investigation, Inc.

0021-9738/96/05/2183/09 \$2.00

Volume 97, Number 10, May 1996, 2183-2191 assume responsibility for gas exchange (2). The first step of lung water clearance at birth is movement of fluid from the lung lumen into the interstitium, a process believed to be driven by sodium transport across the alveolar epithelium (2). The sodium channel antagonist amiloride blocked induction of lung water reabsorption by epinephrine (3) and dibutyryl cAMP (4); instillation of amiloride down the trachea of neonatal guinea pigs caused hypoxemia and increased extravascular lung water (5). Both fetal (6) and adult (7) type II pneumocytes in culture exhibit amiloride-sensitive sodium reabsorption. Fewer details are known about the second step in perinatal lung water clearance - removal of fluid from the interstitium - though it appears that the predominant pathway for clearance is the circulation rather than the lymphatics (8).

While understanding of the physiology and salt transport pathways of fetal lung development is steadily increasing, the molecular basis for water reabsorption in the perinatal lung remains undefined. Aquaporin-1 (AQP1) ${ }^{1}$ is the first characterized member of a family of proteins which form water-specific channels (9). AQP1 is expressed in several secretory and absorptive epithelia, as well as capillary endothelia in many organs including lung $(10,11)$. Developmental expression of AQP1 is complex, and tissue-specific patterns have been defined in rat $(12,13)$. (a) Prenatal expression of AQP1 occurs in some tissues at the time of first physiological need with downregulation of the mRNA after birth; e.g., expression in cornea coincides with acquisition of transparency. (b) Expression occurs in other tissues throughout prenatal and postnatal life; e.g., expression in the choroid plexus is apparently linked to the secretion of cerebrospinal fluid. (c) Expression is predominantly postnatal in still other tissues; e.g., expression in the proximal nephron closely precedes the ability of the kidneys to conserve water, as needed for survival after weaning, while expression in red cells is thought to enhance their survival as they transit the hypertonic renal medulla. The studies of fetal rat kidney and red cells were found to be relevant to human developmental expression patterns (14).

The roles which aquaporins play in the pathogenesis of several disease states are beginning to emerge (15). Mutations in the renal collecting duct homolog AQP2 are responsible for some forms of nephrogenic diabetes insipidus in humans (16). Mutations in the lens aquaporin MIP (major intrinsic protein) are known to underlie at least one form of congenital cataract in mice $(17,18)$. Worldwide blood group referencing has identified extremely few individuals totally lacking the Colton Blood group antigen. Three Colton-null individuals were found to be homozygous for disruptions of the $A Q P 1$ gene, but surprisingly none suffered any apparent clinical conse-

1. Abbreviations used in this paper: AQP1, aquaporin-1; E, embryonic day; $\alpha \mathrm{rENaC}$, adult rat colonic epithelial sodium channel. 
quence (19). Although no evidence has yet demonstrated that AQP1 may be the rate-limiting factor in pulmonary water transport, the exceedingly low frequency of homozygous mutations in $A Q P 1$ suggests that these individuals may express some compensating factor (19). Since pulmonary dysfunction is a known source of morbidity for premature human infants (20), this study was undertaken to determine the developmental expression, potential hormonal modulation, and distribution of AQP1 in rat lung, in order to evaluate a possible role in perinatal lung water clearance or other developmental processes.

\section{Methods}

Materials. Polyclonal, affinity-purified rabbit antibodies to AQP1 (anti-AQP1), which react with the $4 \mathrm{kD}$ carboxy-terminal domain of the protein (21), and affinity-purified rabbit antibodies to red cell spectrin (22) were previously described. Anti- $\alpha$-actinin anti-serum was the kind gift of Dr. Susan Craig. Electrophoresis reagents were from Bio-Rad (Melville, NY). Enhanced chemiluminescence reagents and $\left[\alpha^{-}{ }^{32} \mathrm{P}\right]-\mathrm{dCTP}$ for Northern blots were from Amersham Corp. (Arlington Heights, IL). Molecular biologic enzymes and reagents were from GIBCO BRL (Gaithersburg, MD). RNAzol B for RNA isolation was from Tel-Test, Inc. (Friendswood, TX). Betamethasone was from Schering Corp. (Kenilworth, NJ). BCA Protein Assay was from Pierce (Rockford, IL). Other reagents and supplies were from Sigma Immunochemicals (St. Louis, MO), J. T. Baker (Phillipsburg, NJ), or Eastman Kodak Co. (Rochester, NY).

Animal protocols. Sprague-Dawley rats (Harlan Sprague-Dawley, Indianapolis, IN) were used in the following series of experiments in which tissues were harvested for protein immunoblots or Northern blot analysis. All animal studies were undertaken with protocols approved by the Johns Hopkins School of Medicine Animal Care and Use Committee.

(a) Lungs were harvested from fetal rats on embryonic day 16 (E16) through E21 (21-d-term), from postnatal rats 1, 2, 4, 8, and $15 \mathrm{~d}$ after birth (noted as $+1,+2,+4,+8,+15$ ), and from adult rats (A). Lung membranes were used for protein immunoblots (see below).

(b) Newborn pups from separate litters were killed at specific intervals during the first $24 \mathrm{~h}$ after birth, and lungs harvested for immunoblots.

(c) Pregnant rats were injected intramuscularly with either betamethasone $(0.35 \mathrm{mg} / \mathrm{kg}$ ) or $0.9 \% \mathrm{NaCl}$ (control; $0.02 \mathrm{ml})$. Rats were injected on two consecutive days, and killed on the third day, which is the age reported. Lungs were isolated from control and steroidtreated fetal rats (E16 to E21) and postnatal rats (+1), as well as from mothers in each group, and used for protein immunoblots.

$(d)$ Kidneys from $(+4)$ and adult rats, blood from $(+1)$ rats, and forepaws from E21 fetal rats were isolated after injection of either $0.9 \% \mathrm{NaCl}$ or betamethasone as in $c$, and used for protein immunoblotting.

(e) 7-d-old rat pups $(+7)$ received a single injection of either $0.9 \%$ $\mathrm{NaCl}(0.02 \mathrm{ml})$ or betamethasone $(0.35 \mathrm{mg} / \mathrm{kg})$, and were killed at baseline, 12, and $24 \mathrm{~h}$ after injection. Lungs were harvested for protein immunoblots or Northern blot analysis. Rats from a single litter were compared at each time point.

Animal tissue harvest. Timed pregnant or adult Sprague-Dawley rats were used in all studies. Animals were allowed free access to food and water until death.

All rats were anesthetized with $\mathrm{CO}_{2}$ and decapitated; fetal rats were decapitated after killing of the mother. The thorax was opened, and the lungs perfused through the right ventricle and pulmonary artery with chilled $5 \mathrm{mM}$ sodium phosphate $(\mathrm{pH} 8.0), 150 \mathrm{mM} \mathrm{NaCl}$, $1 \mathrm{mM}$ EDTA (PBS-EDTA) until free of blood. Perfusion of fetal rats was accomplished with 25-gauge needles. Rats used for harvest of kidneys were perfused through both the right and left ventricle until free of blood. Tissues were removed, frozen on dry ice, and stored at $-85^{\circ} \mathrm{C}$ for subsequent isolation of membranes or RNA (see below). Lungs from fetal rats and 1-d-old rat pups were pooled by litter in order to have adequate sample for processing; specimens from older animals were processed individually.

Tissue membrane preparations. Tissues were homogenized in a Potter-Elvehjem homogenizer on ice in buffer containing $0.25 \mathrm{M}$ sucrose with protease inhibitors $1 \mathrm{mM}$ phenylmethylsulfonyl fluoride, $0.5 \mathrm{mg} / \mathrm{ml}$ diisopropylfluorophosphate, and $4 \mu \mathrm{g} / \mathrm{ml}$ leupeptin. Membranes were isolated by low speed $(800 \mathrm{~g})$ centrifugation of the homogenate, followed by high speed $(200,000 \mathrm{~g})$ centrifugation of the supernatant. Membrane pellets were solubilized in $1.5 \%$ SDS (wt/vol), and total protein concentration was measured spectrophotometrically with the BCA Protein Assay (Pierce), using bovine serum albumin as the standard.

Red blood cell membrane preparation. RBC membranes from both adult and one day old $(+1)$ rats were prepared by five cycles of hypotonic lysis in $5 \mathrm{mM}$ sodium phosphate with the above-listed protease inhibitors, followed by centrifugation at 39,000 $\mathrm{g}$. Membranes were solubilized in $1.5 \%$ SDS (wt/vol).

Electrophoresis and immunoblots. SDS-PAGE was performed using the buffer system of Laemmli (23) and $0.1 \times 9 \times 6 \mathrm{~cm} 12 \%$ acrylamide slabs. $12-15 \mu \mathrm{g}$ total membrane protein was loaded for each sample; SDS-PAGE gels were stained with Coomassie brilliant blue (Bio-Rad) to confirm equivalence of samples. Immunoblotting was performed as described (24), using enhanced chemiluminescence and autoradiography to visualize immunoblots. Contact prints of autoradiographs were made for presentation of data.

Northern blots. RNA was isolated from rat lungs using RNAzol B solution (Tel-Test, Inc., Friendswood, TX). RNA concentrations were assessed spectrophotometrically, and confirmed with formaldehyde agarose gels. $10 \mu \mathrm{g}$ total RNA per sample was resolved on a formaldehyde agarose gel, and transferred to nitrocellulose. Hybridization was performed at high stringency with full length mouse AQP1 cDNA labeled with $\left[a^{-32} \mathrm{P}\right] \mathrm{dCTP}$ as described (25). Blots were visualized by autoradiography. $18 \mathrm{~S}$ ribosomal RNA was visualized by ultraviolet exposure of the nitrocellulose blot (Eagle Eye Systems; Stratagene, La Jolla, CA).

Preparation of tissues for immunocytochemistry. Male Wistar rats (postnatal day 1,14, or 40) were anesthetized, heparinized, and perfusion fixed through the right atrium with $8 \%$ paraformaldehyde in $0.1 \mathrm{M}$ sodium cacodylate buffer ( $\mathrm{pH}$ 7.2). Lungs of fetal pups at embryonic days 15 and 21 (E15, E21) from heparinized, anesthetized pregnant rats were immersion-fixed. Tissue blocks from adult rat lung were postfixed in the same fixative for $2 \mathrm{~h}$, infiltrated for $30 \mathrm{~min}$ with $2.3 \mathrm{M}$ sucrose containing $2 \%$ paraformaldehyde, mounted on holders and rapidly frozen in liquid nitrogen. These blocks were used for freeze-substitution or cryosectioning.

Freeze-substitution of tissue. The frozen samples were freeze-substituted $(26,27)$ in a Reichert AFS (Reichert, Vienna, Austria) or in Balzers freeze-substitution unit (FSU 010, Balzers AG, Liechtenstein). Samples were sequentially equilibrated over $3 \mathrm{~d}$ in $0.5 \%$ uranyl acetate in methanol at temperatures gradually decreasing from $-80^{\circ} \mathrm{C}$ to $-70^{\circ} \mathrm{C}$, then rinsed in pure methanol for $24 \mathrm{~h}$ at -70 to $-45^{\circ} \mathrm{C}$. At $-45^{\circ} \mathrm{C}$ the samples were serially infiltrated with Lowicryl HM 20 and methanol 1:1, 2:1 and finally pure HM20, before UV-polymerization for $2 \mathrm{~d}$ at $-45^{\circ} \mathrm{C}$ and $2 \mathrm{~d}$ at $0^{\circ} \mathrm{C}$.

Immunohistochemistry and immunoelectronmicroscopy. For light microscopic observations paraffin sections were placed on gelatin coated glass slides, and endogenous peroxidase activity (exclusively in red cells) was blocked by incubation for 20 min with $0.75 \% \mathrm{H}_{2} \mathrm{O}_{2}$ in $75 \%$ methanol, followed by extensive wash in PBS. After preincubation with PBS containing $1 \% \mathrm{BSA}$ and $0.05 \mathrm{M}$ glycine, sections were incubated with anti-AQP1 $(0.1-0.2 \mu \mathrm{g} / \mathrm{ml})$, and visualized with HRPconjugated secondary antibody. Sections were counter-stained with Meier counter-stain. For electron microscopy immunolabeling was performed on ultrathin Lowicryl sections (40-60 nm) or ultrathin cryosections $(80 \mathrm{~nm})$ obtained on a Reichert Ultracut FSC ultracryomi- 

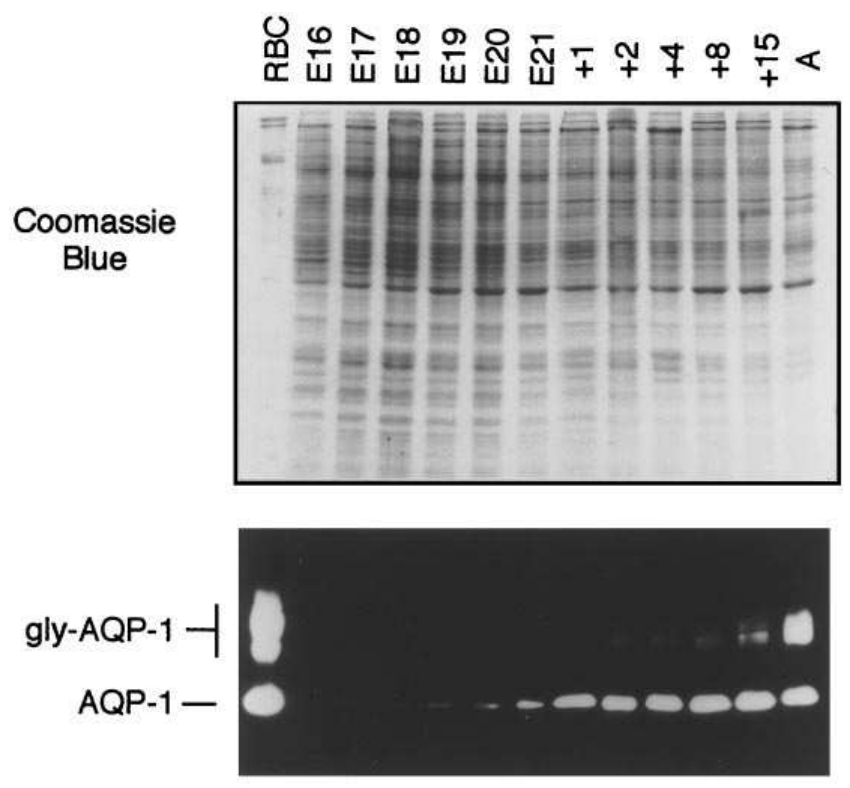

$\alpha$-actinin -

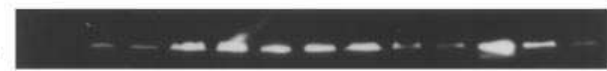

Figure 1. Anti-AQP1 immunoblots of rat lung membranes from embryonic day $16(E 16)$ to adult $(A) .12-15 \mu \mathrm{g}$ total membrane protein were electrophoresed into $12 \%$ SDS-PAGE slabs and stained with Coomassie blue or immunoblotted with affinity-purified anti-AQP1 antibody (see Methods). Adult rat red blood cell membranes $(R B C)$ were included as a positive control. The stripped blot was incubated with antiserum raised to $\alpha$-actinin.

crotome. The sections were incubated with anti-AQP1 and labeling was visualized with goat anti-rabbit gold $(10 \mathrm{~nm})$. The sections were stained with uranyl acetate for $10 \mathrm{~min}$.

Immunolabeling controls. The following controls were performed at the light and electron microscopic level: $(a)$ incubation with protein-A-purified rabbit $\operatorname{IgG} ;(b)$ adsorption of anti-AQP1 $(0.1 \mu \mathrm{g} / \mathrm{ml})$ with purified AQP1 $(10 \mu \mathrm{g} / \mathrm{ml})$; and (c) incubation without primary antibody or without primary and secondary antibody. All controls revealed absence of labeling.

Densitometry. The $28-\mathrm{kD}$ signal of AQP1 on protein immunoblots (area, $\mathrm{mm}^{2}$ ) was quantitated by densitometric scanning of autoradiographs with an UltroScan XL laser densitometer (Pharmacia LKB Biotechnology Inc., Piscataway, NJ). The AQP1 signal on Northern blots was quantitated by phosphoimager (Fuji, Stamford, CT).

Statistics. Densitometric analysis of immunoblots is expressed as mean \pm range, or mean \pm standard error of the mean (SEM) for each group. The effect of corticosteroids at multiple gestational ages was assessed by two factor ANOVA (treatment, time). Assessment of steroid effects in other experiments was determined with nonpaired $t$ tests. Significance was established as $P<.05$.

\section{Results}

Developmental expression of aquaporin-1 in rat lung. Lung membranes of fetal rats from embryonic day 16 (E16) through E21 (full term), and postnatal rats from one day after birth $(+1)$ through adult, were examined by anti-AQP1 immunoblot (Fig. 1). Equivalent lung membrane sample loadings were confirmed by Coomassie staining (Fig. 1, top). As a positive control, red blood cell (RBC) membranes demonstrated the $28-\mathrm{kD}$ AQP1 subunit and the 40-60-kD glycosylated AQP1 subunit
A

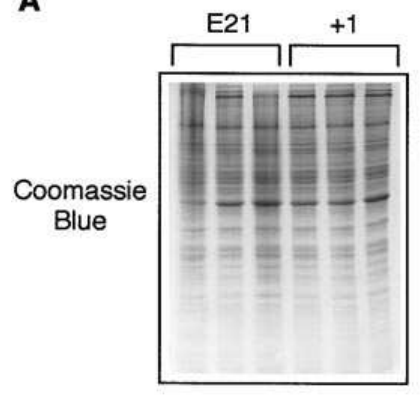

B
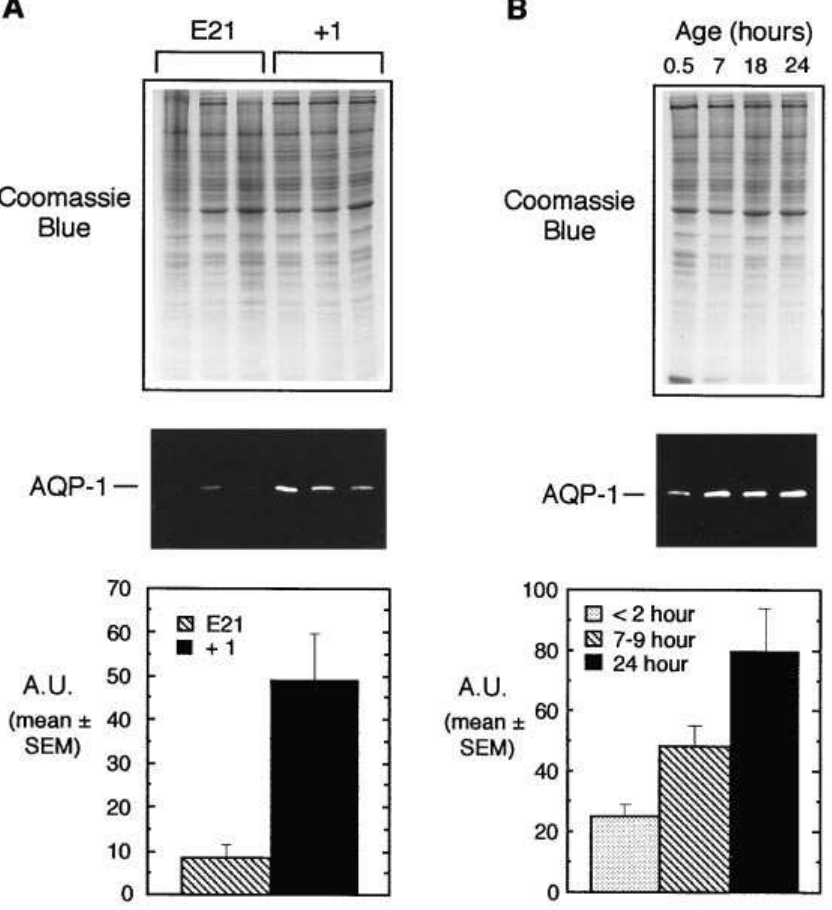

Figure 2. AQP1 expression in perinatal rat lung. $(A)$ Lung membranes were prepared from pooled litters of rats from embryonic day $21(E 21)$ or postnatal day $1(+1)$ for SDS-PAGE and immunoblot. Each lane represents pooled membranes from a separate litter. Immunoblots were analyzed by densitometry, and the results expressed in arbitrary absorption units $(A . U$. $)$ as mean \pm SEM for each age $(P<$ $.05)$. (B) Lung membranes were prepared from rat pups of a single litter at the times noted after birth. Immunoblots from three separate litters were compared by densitometry, and the results combined for the times noted (7-9 h NS; 24 h $P<.05$ compared with baseline).

(gly-AQP1; Fig 1., middle) (23). AQP1 was expressed in fetal rat lung at E19 (Fig. 1, middle); rarely, AQP1 was found in fetal lung samples at E17 or E18. AQP1 in lung increased fourto fivefold from E20 to E21 (densitometric analysis, data not shown), and fivefold from E21 to the first postnatal day, +1 (see below). The rapid increase in lung AQP1 expression from E20 to +1 was followed by a slower increase over the first two weeks of postnatal life. AQP1 expression was sustained at high levels in adult rat lung. AQP1 is substoichiometrically glycosylated (21), but gly-AQP1 was not visible prior to postnatal day 2 without overloading the gel (Fig. 1). In contrast, $\alpha$-actinin, a membrane-associated protein (28), was present in lung membranes at all ages (Fig. 1, bottom). Spectrin was not present in lung membranes at any age by immunoblot, confirming the lack of RBC contamination (data not shown).

To confirm that lung AQP1 was markedly increasing at birth, AQP1 expression was compared in multiple litters of E21 and +1 animals ( $n=3$ each group; Fig. $2 A$ ). Total membrane samples from the two groups were similar, but the immunoblot demonstrated that AQP1 increased in the lung of all +1 rat pups by approximately fivefold compared with E21 fetuses (Fig. $2 A$, top, middle; $P<.05$ ). To examine the rate of increase during the day after birth, lungs were harvested at intervals over the first $24 \mathrm{~h}$ after parturition. The immunoblot of lung membranes from a representative litter is shown (Fig. 2 $B$, top, middle). Pooled data from three litters (Fig. 2 B, bot- 
A
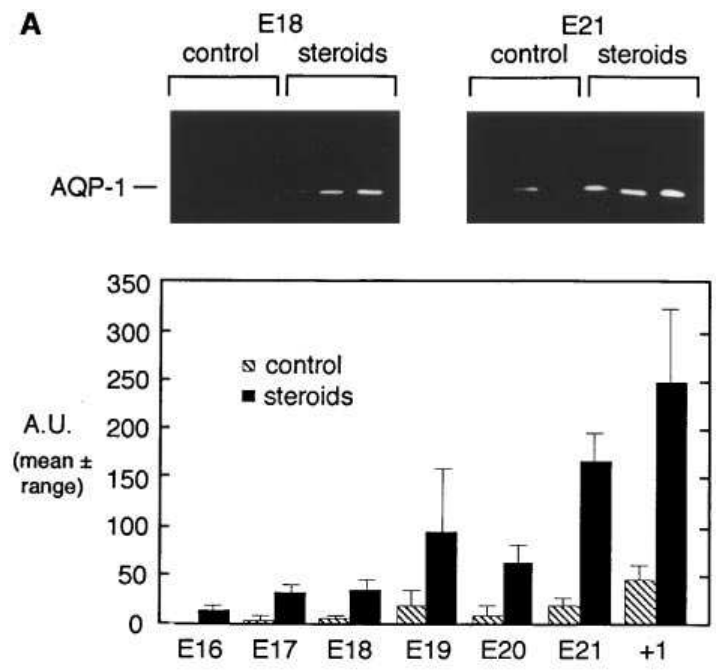

B
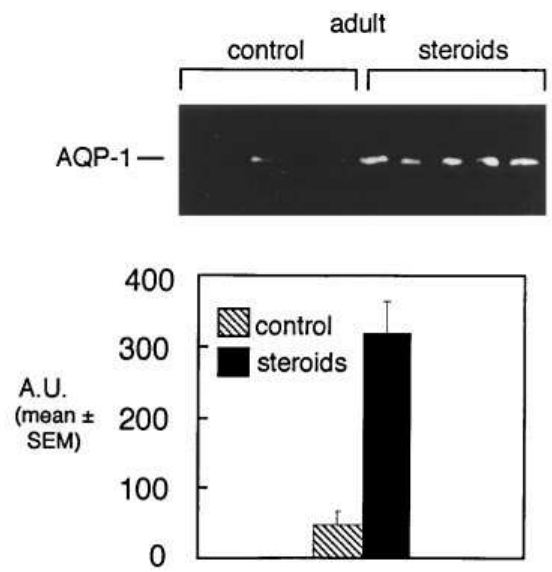

Figure 3. AQP1 expression in fetal and adult rat lung after corticosteroid administration. Pregnant rats were injected on successive days with physiological saline $(0.02 \mathrm{ml})$ or betamethasone $(0.35 \mathrm{mg} / \mathrm{kg})$, and both fetal and adult lungs were harvested on a third day. Lung membranes were analyzed by SDS-PAGE and immunoblot. $(A)$ Representative immunoblots from fetal lung membranes on embryonic days 18 (E18) and 21 (E21) are shown. Immunoblots from embryonic day 16 to postnatal day 1 were compared by densitometry and expressed in arbitrary absorption units $(A . U$.) as mean \pm range $(P<.001$ for steroid effects). (B) Immunoblot of control and steroid-treated adult rat lung membranes with densitometric analysis expressed as mean $\pm \operatorname{SEM}(P<.001)$.

tom) demonstrates that AQP1 in rat lung doubled over the first 7-9 $\mathrm{h}$ after birth (NS), and was threefold greater than baseline at $24 \mathrm{~h}(P<.05)$. Five litters of fetal rats age E19-E21 were divided by gender, but no differences in AQP1 expression were noted (data not shown).

Effect of corticosteroids on aquaporin-1 expression. Steroid effects on expression of AQP1 in lung were assessed by immunoblotting lung membranes from fetal rats of mothers injected with either corticosteroids or saline. Representative immunoblots of lung membranes from control and steroid-treated E18 and E21 fetal rats ( $n=3$ litters in each group) are shown (Fig. 3 A, top). Densitometry of a series of immunoblots demonstrated that maternal corticosteroid administration increased the expression of AQP1 in the fetal lungs (Fig. 3 A, bottom; $n=$
A
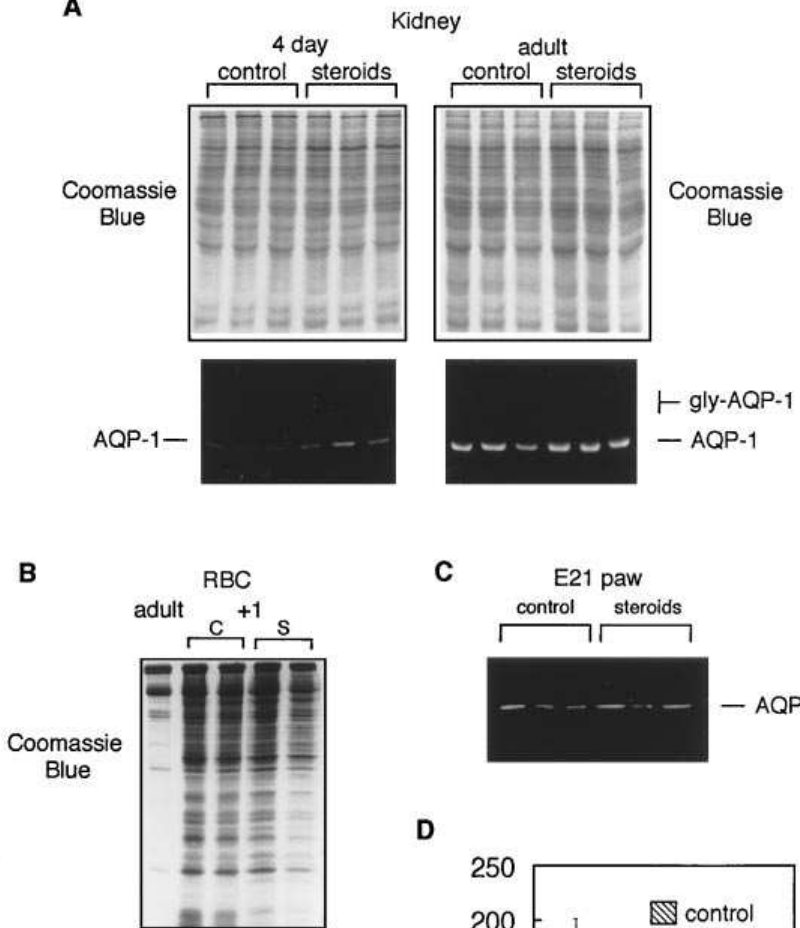

C

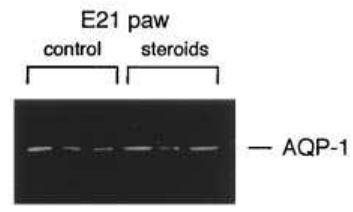

D
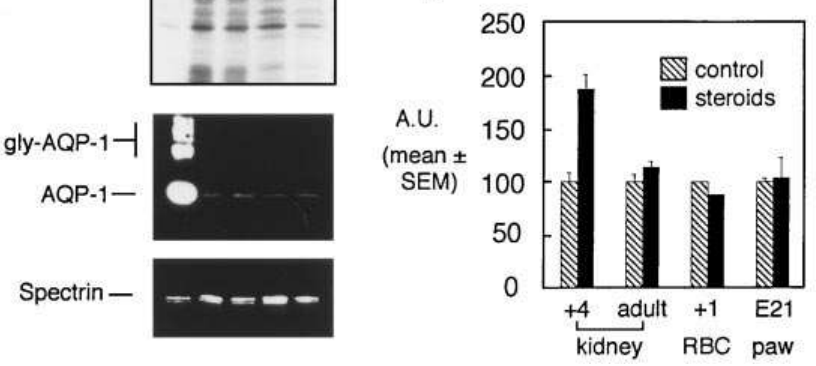

Figure 4. Effects of corticosteroid administration on AQP1 expression in rat extrapulmonary tissues. Rats were injected with two daily injections of either physiological saline $(0.02 \mathrm{ml}$; control $)$ or betamethasone $(0.35 \mathrm{mg} / \mathrm{kg})$, and tissues harvested at the designated ages. $(A)$ Kidney membranes from 4 -d-old and adult rats were analyzed by SDS-PAGE and immunoblot. $(B)$ RBC membranes from adult rat red cells and control $(C)$ or steroid-treated $(S)$ postnatal day $1(+1)$ animals were analyzed by SDS-PAGE and immunoblot. The blot was then stripped, and reprobed with anti-spectrin to confirm equivalence of membrane loading. $(C)$ Immunoblot of forepaws from E21 fetuses. (D) Densitometric analysis of immunoblots from $A-C$ expressed in arbitrary absorption units as mean \pm SEM with control set at $100 \%$ ( $4 \mathrm{~d}$ kidney $P<.05$; others NS).

3 litters per group except E16 $(n=2) ; P<.001)$. To determine if corticosteroid induction of AQP1 in the lung was limited to fetal animals, lung membranes from control and steroid-treated pregnant adult rats were immunoblotted with anti-AQP1 (Fig. $3 B ; n=5$ each group). AQP1 expression was increased sixfold in steroid-treated adult rats compared with controls (Fig. 3 B, bottom; $P<.001$ ).

To determine if corticosteroid-induction of AQP1 was global or tissue-specific, steroid effects were assessed in nonpulmonary tissues. AQP1 is abundant in renal proximal tubule, where it is first expressed shortly before birth (13). Immunoblots of membranes from whole kidney of +4 and adult rats treated with $0.9 \% \mathrm{NaCl}$ or betamethasone revealed approximately twofold induction of AQP1 by corticosteroids in 4-d-old rats $(P<.05)$, but no induction in adult rats (NS; Fig. 4, $A$ and 
D). RBCs contain abundant AQP1 $(21,29)$, but not until after birth in the rat (13). RBC membranes were prepared from +1 rat pups of mothers injected with corticosteroids or saline. Equivalent sample loadings were confirmed by Coomassie staining or immunoblotting with anti-spectrin (Fig. 4 B, top, bottom). Immunoblotting demonstrated that AQP1 was not increased in RBCs from the steroid-treated animals (Fig. $4 B$, middle and $4 D$ ). In addition, expression of AQP1 message in long bones such as the forepaw has previously been demonstrated (12). Forepaws were harvested from control and steroid-treated E21 fetal rats, but steroid-induction of AQP1 expression was not observed (Fig. 4, $C$ and $D$; NS).

To explore potential mechanisms of AQP1 induction by corticosteroids, 7-d-old rat pups received a single injection of saline or betamethasone, and lungs were harvested at baseline, $12 \mathrm{~h}$, and $24 \mathrm{~h}$ after injection for isolation of membranes or RNA for Northern analysis (Fig. $5 \mathrm{~A}$ ). $12 \mathrm{~h}$ after injection, AQP1 message was increased in steroid-treated rats by threefold over control $(P<.05) ; 24 \mathrm{~h}$ after injection AQP1 message levels were again similar in the two groups (NS; Fig. 5, $A$ and $B)$. AQP1 protein expression was assessed by immunoblotting lung membranes from the two groups (Fig. $5 C$ ). Densitometry of the immunoblots revealed that lung AQP1 protein levels were not different $12 \mathrm{~h}$ after injection (NS), but steroid-treated animals had $50 \%$ more AQP1 in lung than controls at $24 \mathrm{~h}(P<$ .05 ; Fig. $5 D$ ).

Distribution of AQP1 in developing rat lung. AQP1 distribution was assessed by immunohistochemical analysis of fetal (E15 and E21) and postnatal (1, 14, and $40 \mathrm{~d}$ old) rat lung (Fig. 6). AQP1 staining was absent from rat lung at E15 (Fig. $6 a$ ), but was strongly present in choroid plexus of the same fetuses (Fig. 6 b). Preadsorption controls were negative in E15 choroid plexus (Fig. $6 c$ ) and 1-d-old lung (Fig. $6 i$ ). At E21, visceral pleura exhibited strong labeling for AQP1 (Fig. $6 d$ ), as did peribronchial capillaries (Fig. $6 e$ ), similar to that seen in peribiliary capillaries and biliary ductules (Fig. $6 f$ ) and intracardiac vessels (Fig. $6 g$ ) at E21. By postnatal day 1, AQP1 was more abundant in both visceral pleura (Fig. $6 h$ ) and peribron- chiolar capillaries (Fig. $6 j$ ); occasional alveolar pneumocytes were labeled. On postnatal day $14 \mathrm{AQP1}$ expression in venules as well as peribronchiolar vessels was noted, with increased labeling of scattered alveolar epithelial cells (Fig. $6 k$ ). At postnatal day 40 , abundant labeling of interstitial peribronchiolar capillaries was evident; capillaries in the submucosal space were also labeled. Bronchiolar epithelium was consistently unlabeled (Fig. $6 l$ ).

Immunoelectron microscopic evaluation of AQP1 distribution in rat lung confirmed the observations made by immunohistochemistry. AQP1 was demonstrated in both the apical and basal plasma membrane of peribronchiolar capillary endothelial cells (EN; Fig. 7, $a$ and $b$ ). AQP1 was not detected in capillary endothelial cells of the thin (EN; Fig. $7 c$ ) or thick (data not shown) portions of the alveolus. Epithelial cells, including type II (Fig. $7 b$, lower left) and type I (EP; Fig. $7 c$ ) pneumocytes did not exhibit AQP1 labeling by electron microscopy in the rat.

\section{Discussion}

The understanding of perinatal lung development will remain incomplete until the molecules determining the major transport pathways are defined. Our studies of fetal rat lung document that AQP1 expression first appears late in gestation, increases prior to birth, and is sustained at high levels in adult animals. The specific appearance of AQP1 in lung at E19 and the severalfold increase from E20 to the first postnatal day parallels the transition from secretion to absorption in the developing lung (2). Moreover, the ontogeny of AQP1 in fetal lung is remarkably similar to that of the sodium channel, $\alpha \mathrm{rENaC}$ (30), and the sodium pump, $\mathrm{Na}+\mathrm{K}+$-ATPase (31, 32). Although it seems unlikely that expression of AQP1 is rate-limiting for perinatal lung water clearance, our studies are consistent with participation of AQP1 in that process.

Administration of corticosteroids will improve pulmonary functions in premature human infants, although the rationale is still largely empirical (33). Our studies revealed that corti-
A
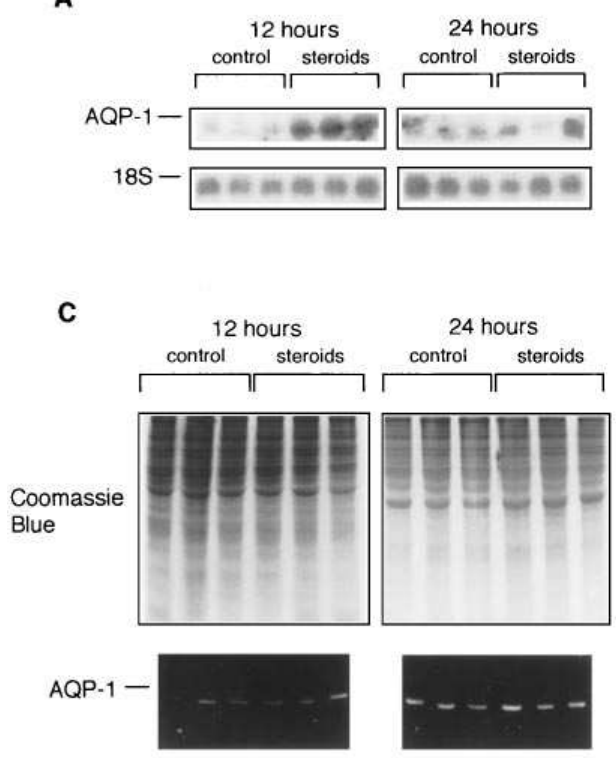

B

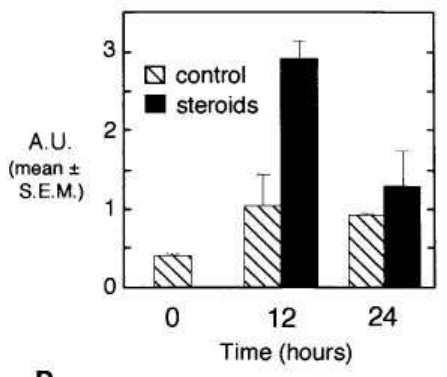

D

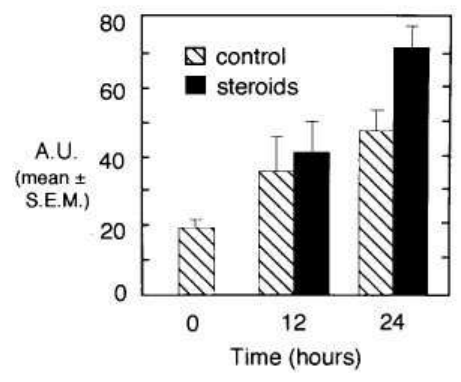

Figure 5. AQP1 expression in rat pup lung after corticosteroid administration. 7-d-old rat pups were injected intramuscularly with physiological saline $(0.02 \mathrm{ml})$ or betamethasone $(0.35 \mathrm{mg} /$ $\mathrm{kg}$ ); lungs were harvested before, 12 , or $24 \mathrm{~h}$ after injection for preparation of lung membranes or isolation of total RNA. Rats from a single litter were used for each time point in order to control for inter-litter variability. (A) $10 \mu \mathrm{g}$ total RNA from control and steroid-treated rat lungs was electrophoresed into a formaldehyde agarose gel, transferred to nitrocellulose, and probed with full length mouse AQP1 cDNA labeled with $\left[\alpha{ }^{32} \mathrm{P}\right] \mathrm{dCTP}$. 18S ribosomal RNA visualized on the nitrocellulose by UV light is shown below. (Preinjection data not shown). (B) AQP1 signal on the Northern blot was quantitated by Phosphorimager; results are expressed in arbitrary absorption units $(A . U$.$) as$ mean \pm SEM $(12$ h $P<.05 ; 24$ h NS). (C) Lung membranes were analyzed by SDS-PAGE and immunoblot. $(D)$ Immunoblots were analyzed by densitometry; results are expressed as in $B$ (12 h NS; 24 h $P<.05$ compared with baseline). 


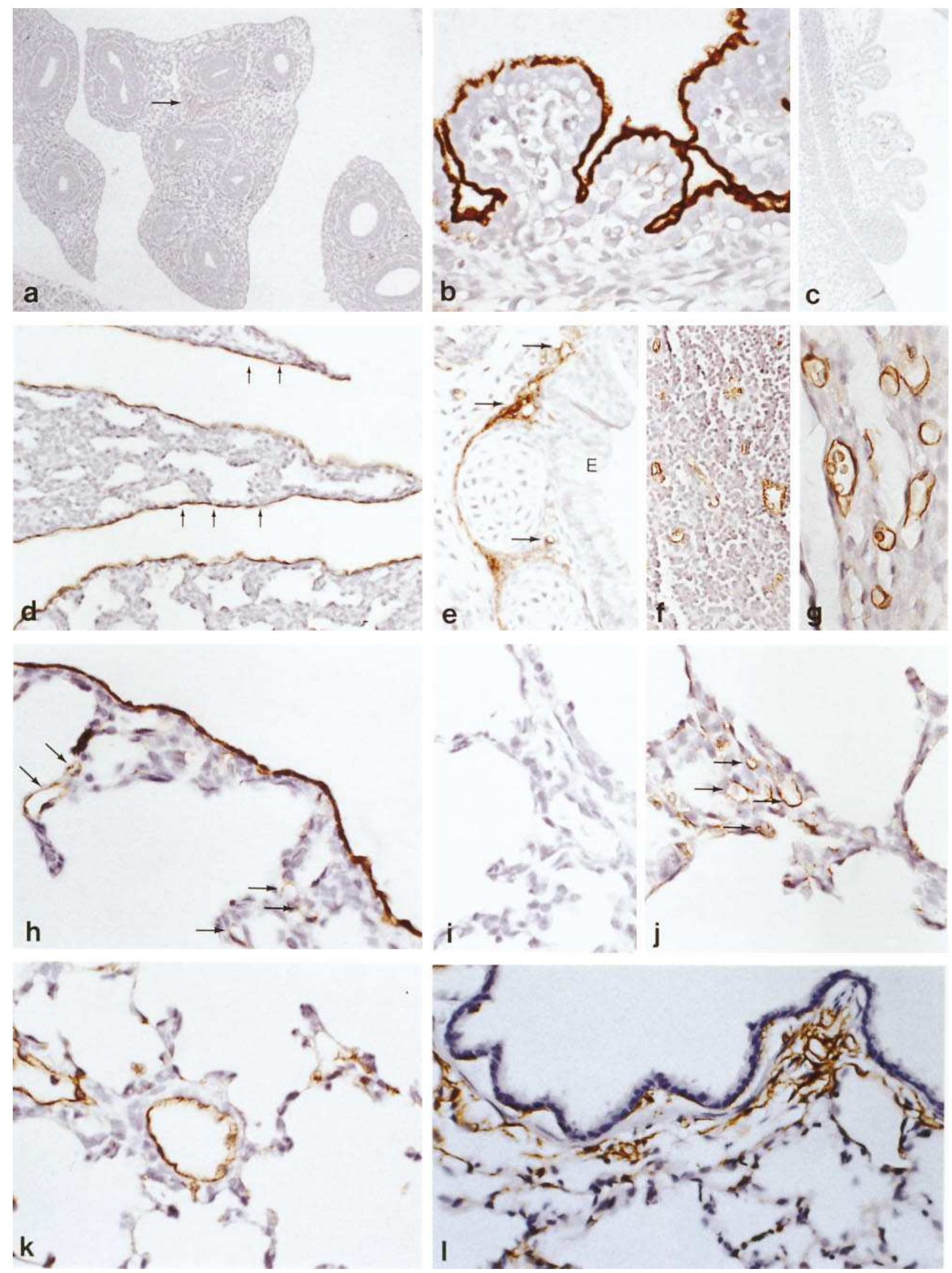

Figure 6. Immunohistochemical localization of AQP1 in rat lung and other tissues at embryonic days E15 ( $a-c)$, E21 (d-g), postnatal days +1 $(h-j),+14(k)$ and $+40(l)$. Paraffin sections were incubated with anti-AQP1; immunolabeling controls in $c$ and $i$ were incubated with anti-AQP1 preadsorbed with purified AQP1. $(a-c)$ At E15, virtually no labeling was observed in lung $(a)$, while choroid plexus was abundantly labeled $(b)$; choroid plexus control was negative $(c) .(d-g)$ At E21 mesothelium of visceral pleura was strongly labeled $(d$, arrows), as was a peribronchial 
costeroids increased the level of AQP1 expression in lung. This effect appears to be tissue-specific, since corticosteroids produced only a low-level induction of AQP1 in 4-d-old rat kidney and had no effect in adult kidney, red cells, and developing long bone in forepaw. Of note, it has recently been demonstrated that AQP2 is induced by corticosteroids in perinatal but not adult kidney (34). Corticosteroid induction of AQP1 in lung is consistent with other observations suggesting hormonal modulation of lung development. Triiodothyronine and cortisol accelerate lung water clearance in thyroidectomized sheep $(35,36)$ and accelerate expression of sodium channels in fetal rat lung (30). Surfactant proteins, integral to the function and homeostasis of the surfactant system, have a very similar ontogeny in lung to AQP1 (37). In contrast to AQP1, genderspecific differences in surfactant phospholipid expression have been demonstrated in fetal animals (38), though it is less clear that fetal surfactant protein expression is gender-dependent (39). While their regulation is likely complex, surfactant proteins are induced in both fetal $(37,39)$ and adult animals $(40)$ by corticosteroids. The dose of corticosteroids used in our studies $(0.35 \mathrm{mg}$ betamethasone $/ \mathrm{kg})$ is approximately twice the dose used clinically for premature labor in many hospitals. Interestingly, administration of $1.0 \mathrm{mg} / \mathrm{kg}$ betamethasone will induce surfactant proteins (39), but did not induce AQP1 expression in fetal lung at E19 or E21 (data not shown). Since therapeutic windows for induction of AQP1, surfactant phospholipids and proteins, and sodium channels may be distinct, definition of the corticosteroid response patterns may permit design of improved therapies for the premature infant.

The effect of corticosteroids on expression of AQP1 in lung was not limited to the fetal period. Steroid-treated pregnant rats exhibited a sixfold increase in lung AQP1 over salinetreated controls. The increase in AQP1 mRNA in lung following corticosteroid administration suggests that at least partial regulation of steroid-induced AQP1 expression is at the level of transcription, and a functional glucocorticoid response element (GRE) has recently been identified in the AQP1 promoter (Moon, King, and Agre, unpublished observations). It remains to be established if some of the known beneficial effects of corticosteroids in certain pulmonary disorders of adults may be explained by the induction of AQP1.

Our studies demonstrated that AQP1 was present in peribronchial vasculature and visceral pleura of rat lung at E21, and expression was further increased postnatally. No AQP1 expression was observed in airway epithelium, and only occasional alveolar pneumocytes were labeled. The first step of perinatal lung water clearance is thought to be across the epithelial barrier into the interstitium. The minimal or absent expression of AQP1 in most alveolar epithelium predicts that other pathways must reside at that location, and the existence of AQP5 in the alveolar type I pneumocytes has been identified (41).

At birth, fluid has been shown to collect in the peribronchiolar interstitial space before reabsorption into the circula- tion $(8,42)$. When filtered through pulmonary microvasculature or after crossing alveolar membranes, fluid moves from a low compliance peripheral compartment into the high compliance peribronchiolar interstitium (43) where the extensive vascular plexus of the bronchial circulation (44) is believed to mediate clearance of interstitial edema $(45,46)$. Abundance of AQP1 in peribronchiolar vessels may suggest a role in clearance of water from the interstitial space. Fluid collects in the peribronchiolar interstitial space before extending into alveoli in models of pulmonary edema (47), a phenomenon which may in part be mediated by AQP1 in those vessels. Similarly, the presence of AQP1 in the visceral pleura may suggest participation in the generation or absorption of pleural fluid or effusions.

Immunoelectron microscopy revealed that AQP1 was expressed on both luminal and basolateral membranes of endothelial cells. While it is attractive to postulate transcellular movement of water through AQP1 in the lung, the role of water channels in lung endothelium (and mesothelium) may not be so straightforward. The predominant model of endothelial permeability suggests that water movement across the membrane occurs by a paracellular path under the influence of Starling forces with large pores mediating clearance of water and solute (48). The lung is not believed to have standing osmotic gradients as a driving force for water channels, and experiments demonstrating the presence of AQP1 and Hg-inhibitable water movement across descending vasa recta of the kidney (49) and peritoneum (50) may not be directly analogous to the lung. $\mathrm{HgCl}_{2}$ has been shown to inhibit water movement into the alveolar space of an in situ perfused sheep lung following instillation of hypertonic solution into the airway (51). Although this was interpreted as representing the function of water channels at an undefined anatomic level between blood and alveolus (51), toxicity of $\mathrm{HgCl}_{2}$ remains a possible issue. AQP1 is enriched in caveolae-containing fractions of lung endothelium, and $\mathrm{Hg}$-inhibitable movement of water across pulmonary vessels into the interstitium has recently been described (52). Despite these suggestions, it remains possible that AQP1 is a principal participant in volume regulation in lung endothelial cells rather than a mechanism for transcellular water movement. Epithelial (53) and endothelial cells (54) have been noted to change volume in response to a variety of stimuli, and changes in cell shape and volume may participate in regulation of paracellular channels in endothelium.

While the ontogeny, steroid-responsiveness, and distribution of AQP1 in rat lung suggest a role for AQP1 in perinatal lung water clearance and portend function in later life, the absence of AQP1 in alveolar epithelium predicts existence of another water channel in that location. Nevertheless, dynamic regulation of AQP1 expression in lung by endogenous mechanisms may prove central to both normal physiology and pathophysiology, and may ultimately provide a target for pharmacologic manipulation of lung water permeability both in prematurity and other pulmonary disorders.

capillary plexus (e, arrows), while bronchial epithelium was unlabeled $(E)$. Abundant AQP1 labeling was seen in peribiliary capillaries and biliary ductules $(f)$, and capillaries and postcapillary venules in heart $(g)$. $(h-j)$ At postnatal day +1 , strong labeling of pleura and periobronchiolar capillaries (arrows) was seen; rare pneumocytes were labeled. $(k)$ At day +14 , increased labeling was observed in peribronchiolar capillaries and larger venules; occasional pneumocytes were distinctly labeled. $(l)$ At day +40 , a capillary plexus external to the bronchiolar smooth muscle layer was strongly labeled, with less prominent submucosal labeling; bronchiolar epithelium was unlabeled. $(a$ and $c) \times 100 ;(b, g-l) \times 500 ;(d-f)$ $\times 250$. 

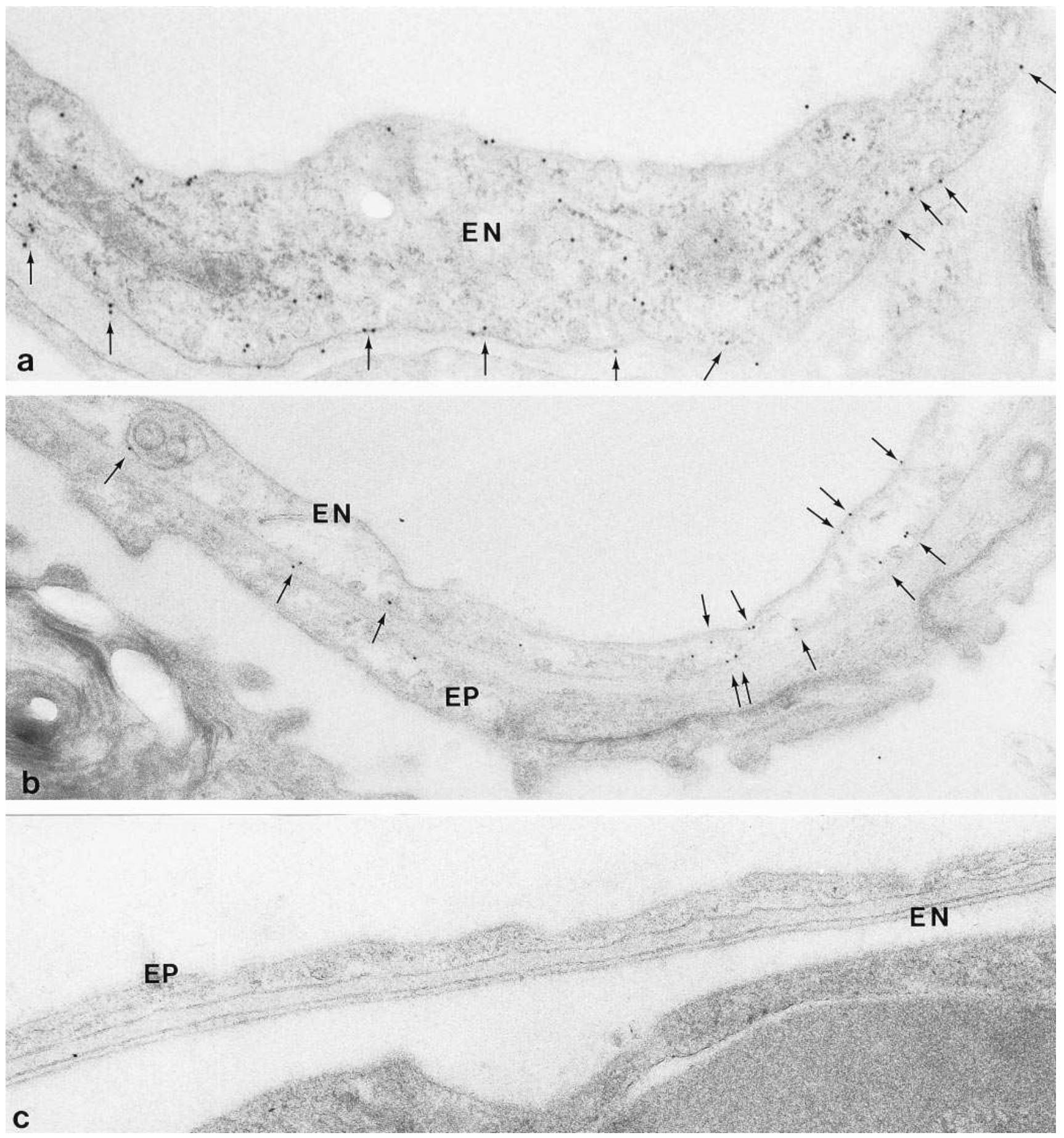

Figure 7. Immunoelectron microscopic localization of AQP1 in vascular structures of adult rat lung. (a) AQP1 labeling is seen in both apical and basal plasma membranes (arrows) of peribronchiolar capillary endothelial cell $(E N)$. $\times 45,000$. (b) Apical and basal plasma membranes of peribronchiolar capillary endothelial cell (EN) exhibit AQP1 labeling (arrows); both type I (EP) and type II (with granule, lower left) epithelial cells are without labeling. $\times 31,000$. (c) Alveolar capillary endothelium $(E N)$ and type-1 epithelium $(E P)$ exhibit no labeling or sparse labeling. $\times 34,000$.

\section{Acknowledgments}

We thank B. L. Smith, G. M. Preston, and C. Moon for technical assistance, and Charles Wiener for assistance with statistical analysis.

Support for this study was provided by National Institutes of Health grants HL-33991 and HL-48268 (P. Agre); NRSA HL-0911902 (L.S. King); the Danish Medical Research Council, Novo Nordic Foundation, University of Aarhus Research Foundation, the Danish
Foundation for the Advancement of Medical Science, the Biomembrane Research Center at the Univerity of Aarhus, and Kong Kristian den tiendes Fond (S. Nielsen).

\section{References}

1. Olver, R.E. 1994. Fluid secretion and absorption in the fetus. In Fluid and Solute Transport in the Airspaces of the Lungs. R.M. Effros, H.K. Chang. Mar- 
cel Dekker, New York. 281-302.

2. Bland, R.D., and D.L. Chapman. 1994. Absorption of liquid from the lungs at birth. In Fluid and Solute Transport in the Airspaces of the Lungs. R.M. Effros, H.K. Chang. Marcel Dekker, New York. 303-322.

3. Olver, R.E., C.A. Ramsden, L.B. Strang, and D.V. Walters. 1986. The role of amiloride-blockable sodium transport in adrenaline-induced lung liquid reabsorption in the fetal lamb. J. Physiol. (Lond.). 376:321-340.

4. Walters, D.V., C.A. Ramsden, and R.E. Olver. 1990. Dibutyryl cyclic AMP induces a gestation-dependent absorption of fetal lung liquid. J. Appl. Physiol. 68:2054-2059.

5. O'Brodovich, H., V. Hannam, M. Seear, and J.B.M. Mullen. 1990. Amiloride impairs lung water clearance in newborn guinea pigs. J. Appl. Physiol. 68:1758-1762.

6. O'Brodovich, H., B. Rafii, and M. Post. 1990. Bioelectric properties of fetal and alveolar epithelial monolayers. Am. J. Physiol. 258:L201-L206.

7. Mason, R.J., M.C. Williams, J.H. Widdicombe, M.J. Sanders, D.S. Misfeldt, and L.G. Berry, Jr. 1982. Transepithelial transport by pulmonary alveolar type II cells in primary culture. Proc. Natl. Acad. Sci. USA. 79:6033-6037.

8. Bland, R.D., T.N. Hansen, C.M. Haberkern, M.A. Bressack, T.A. Hazinski, J.U. Raj, and R.B. Goldberg. 1982. Lung fluid balance in lambs before and after birth. J. Appl. Physiol. 53:992-1004.

9. Agre, P., G.M. Preston, B.L. Smith, J.S. Jung, S. Raina, C. Moon, W.B. Guggino, and S. Nielsen. 1993. Aquaporin CHIP, the archetypal molecular water channel. Am. J. Physiol. 265:F463-476.

10. Nielsen, S., B.L. Smith, E.I. Christensen, and P. Agre. 1993. Distribution of the aquaporin CHIP in secretory and resorptive epithelia and capillary endothelia. Proc. Natl. Acad. Sci. USA. 90:7275-7279.

11. Nielsen, S., B.L. Smith, E.I. Christensen, M.A. Knepper, and P. Agre. 1993. CHIP28 water channels are localized in constitutively water-permeable segments of nephron. J. Cell Biol. 120:371-383.

12. Bondy, C., E. Chin, B.L. Smith, G.M. Preston, and P. Agre. 1993. Developmental gene expression and tissue distribution of the CHIP28 water channel protein. Proc. Natl. Acad. Sci. USA. 90:4500-4504.

13. Smith, B.L., R. Baumgarten, S. Nielsen, D.M. Raben, M.L. Zeidel, and P. Agre. 1993. Concurrent expression of erythroid and renal aquaporin CHIP and appearance of water channel activity in perinatal rats. J. Clin. Invest. 92: 2035-2041.

14. Agre, P., B.L. Smith, R. Baumgarten, G.M. Preston, E. Pressman, P. Wilson, N. Illum, D.J. Anstee, M.B. Lande, and M.L. Zeidel. 1994. Human red cell Aquaporin CHIP. II. Expression during normal fetal development and in a novel congenital dyserythropoietic anemia. J. Clin. Invest. 94:1050-1058.

15. King, L.S., and P. Agre. 1996. Pathophysiology of the aquaporin water channels. Annu. Rev. Physiol. 58:619-648.

16. Deen, P.M.T., M.A.J. Verdijk, N.V.A.M. Knoers, B. Wieringa, L.A.H. Monnens, C.H. van Os, and B.A. van Oost. 1994. Requirement of human renal water channel aquaporin-2 for vasopressin-dependent concentration of urine. Science (Wash. DC). 264:92-95.

17. Muggleton-Harris, A.L., M.F.W. Festing, and M. Hall. 1987. A gene location for the inheritance of the Cataract Fraser $\left(\mathrm{Cat}^{\mathrm{Fr}}\right)$ mouse congenital cataract. Genet. Res. 49:235-238.

18. Shiels, A., and S. Bassnett. 1996. Mutations in the founder of the MIP gene family underlie cataract development in the mouse. Nat. Genet. 12:212215 .

19. Preston, G.M., B.L. Smith, M.L. Zeidel, J.J. Moulds, and P. Agre. 1994. Mutations in Aquaporin-1 in phenotypically normal humans without functional CHIP water channels. Science (Wash. DC). 265:1585-1587.

20. Jobe, A. 1984. Respiratory distress syndrome - new therapeutic approaches to a complex pathophysiology. Adv. Pediatr. 30:93-130.

21. Smith, B.L., and P. Agre. 1991. Erythrocyte Mr 28,000 transmembrane protein exists as a multi-subunit oligomer similar to channel proteins. J. Biol. Chem. 266:6407-6415.

22. Agre, P., J.F. Casella, W.H. Zinkham, C. McMillan, and V. Bennett. 1985. Partial deficiency of erythrocyte spectrin in hereditary spherocytosis. $\mathrm{Na}$ ture (Lond.). 314:380-383.

23. Laemmli, U.K. 1970. Cleavage of structural proteins during assembly of the head of bacteriophage $\mathrm{T}_{4}$. Nature (Lond.). 227:680-685.

24. Davis, J.Q., and V. Bennett. 1984. Brain ankyrin: purification of a 72,000 $M_{\mathrm{r}}$ spectrin-binding domain. J. Biol. Chem. 259:1874-1881.

25. Preston, G.M., and P. Agre. 1991. Molecular cloning of the red cell integral protein of $M_{\mathrm{r}}$ 28,000: A member of an ancient channel family. Proc. Natl. Acad. Sci. USA. 88:11110-11114.

26. Nielsen, S., T. Pallone, B.L. Smith, E.I. Christensen, P. Agre, and A.B. Maunsbach. 1995. Aquaporin-1 water channels in short and long loop descending thin limbs and in descending vasa recta in rat kidney. Am. J. Physiol. 268: F1023-F1037.

27. Maunsbach, A.B. 1994. Embedding of cells and tissues for ultrastructural and immunocytochemical analysis. In Cell Biology: A Laboratory Hand- book. J. E. Celis. Orlando, FL: Academic. 117-125.

28. Alberts, B., D. Bray, J. Lewis, M. Raff, K. Roberts, and J.D. Watson 1994. Membrane structure. In Molecular Biology of the Cell. Garland Publishing Inc., New York. 492-493.

29. Denker, B.M., B.L. Smith, F.P. Kuhajda, and P. Agre. 1988. Identification, purification, and characterization of a novel $\mathrm{M}_{\mathrm{r}} 28,000$ integral membrane protein from erythrocytes and renal tubules. J. Biol. Chem. 263:15634-15642.

30. O'Brodovich, H., C. Canessa, J. Ueda, B. Rafii, B. C. Rossier, and J Edelson. 1993. Expression of the epithelial $\mathrm{Na}+$ channel in the developing rat lung. Am. J. Physiol. 265:C491-C496.

31. O'Brodovich, H., O. Staub, B. Rossier, K. Geering, and J.-P. Kraehenbuhl. 1993. Ontogeny of $\alpha_{1}$ - and $\beta_{1}$-isoforms of $\mathrm{Na}+-\mathrm{K}+$-ATPase in distal fetal lung epithelium. Am. J. Physiol. 264:C1137-C1143.

32. Orlowski, J., and J.B. Lingrel. 1988. Tissue-specific and developmental regulation of rat $\mathrm{Na}, \mathrm{K}-\mathrm{ATPase}$ catalytic alpha isoform and beta subunit mRNAs. J. Biol. Chem. 263:10436-10442.

33. Ward, R.M. 1994. Pharmacologic enhancement of fetal lung maturation. Clin. Perinatol. 21:523-542.

34. Yasui, M., D. Marples, R. Belusa, A.-C. Eklöf, G. Celsi, S. Nielsen, and A. Aperia. 1996. Development of urinary concentrating capacity: role of aquaporin-2 (AQP2). Am. J. Physiol. In press.

35. Barker, P.M., D.V. Walters, and L.B. Strang. 1990. The role of thyroid hormones in maturation of the adrenaline-sensitive lung-liquid reabsorption mechanism in the fetal sheep. J. Physiol. (Lond.). 424:473-485.

36. Barker, P.M., M. Markiewicz, K.A. Parker, D.V. Walters, and L.B Strang. 1991. Synergistic action of triiodothyronine and hydrocortisone on epinephrine-induced reabsorption of fetal lung liquid. Pediatr. Res. 27:588-591.

37. Mendelson, C.R., and V. Boggaram. 1991. Hormonal control of the surfactant system in fetal lung. Annu. Rev. Physiol. 53:415-440.

38. Torday, J.S., and H.C. Nielsen. 1987. The sex difference in fetal lung surfactant production. Exp. Lung Res. 12:1-19.

39. Schellhase, D.E., and J.M. Shannon. 1991. Effects of maternal dexamethasone on expression of SP-A, SP-B, and SP-C in the fetal rat lung. Am. J. Respir. Cell Mol. Biol. 4:304-312.

40. Floros, J., D.S. Phelps, H.P. Harding, S. Church, and J. Ware. 1989. Postnatal stimulation of rat surfactant protein A synthesis by dexamethasone. Am. J. Physiol. 257:L137-143.

41. King, L.S., S. Nielsen, and P. Agre. 1996. Aquaporin-5 is expressed in rat type I pneumocytes. Am J. Resp. Crit. Care Med. (Abst.) 153:A508.

42. Bland, R.D., D.D. McMillan, M.A. Bressack, and L. Dong. 1980. Clearance of liquid from lungs of newborn rabbits. J. Appl. Physiol. 49:171-177.

43. Conhaim, R.L. 1994. Movement of fluid and particles between the airspaces and pulmonary interstitium. In Fluid and Solute Transport in the Airspaces of the Lungs. R.M. Effros, H.K. Chang. Marcel Dekker, New York. 357374

44. Charan, N.B., and P.G. Carvalho. 1992. Anatomy of the normal bronchial circulatory system in humans and animals. In The Bronchial Circulation. J. Butler. Marcel Dekker, New York. 45-77.

45. Jayr, C., and M.A. Matthay. 1991. Alveolar and lung liquid clearance in the absence of pulmonary blood flow in sheep. J. Appl. Physiol. 71:1679-1687.

46. Matthay, M.A. 1992. The bronchial and systemic circulations in lung and pleural fluid and protein balance. In The Bronchial Circulation. J. Butler. Marcel Dekker, New York. 389-415.

47. Staub, N.C., H. Nagano, M.L. Pearce. 1967. Pulmonary edema in dogs, especially the sequence of fluid accumulation in lungs. J. Appl. Physiol. 22:227240

48. Clough, G. 1991. Relationship between microvascular permeability and ultrastructure. Prog. Biophys. Molec. Biol. 55:47-69.

49. Rippe, B., O. Carlsson, S. Nielsen, and E.R. Zakaria. 1995. Importance of Aquaporin-CHIP (AQP1) in peritoneal dialysis. Aquaporins and Epithelial Water Transport. International Symposium, Manchester, U.K. 1:11 (Abstr.)

50. Pallone, T.L., B.K. Kishore, M.R. Turner, S. Nielsen, P. Agre, and M.A Knepper. 1996. Water flux across outer medullary descending vasa recta mediated by aquaporin-1 water channel. FASEB J. (Abstr.) 10:A575 (Abstr.).

51. Folkesson, H.G., M.A. Matthay, H. Hasegawa, F. Kheradmand, and A.S. Verkman. 1994. Transcellular water transport in lung alveolar epithelium through mercury-sensitive water channels. Proc. Natl. Acad. Sci. USA. 91:4970 4974.

52. Schnitzer, J.E., and P. Oh. 1996. Aquaporin-1 on the plasmalemma and caveolae provides mercury-sensitive transmembrane water channels for endothelium in rat lung. Am. J. Physiol. 39:H416-422.

53. MacLeod, R.J., J.R. Hamilton, H. Kopelman, and N.B. Sweezey. 1994. Developmental differences of cystic fibrosis transmembrane conductance regulator functional expression in isolated rat fetal distal airway epithelial cells. $\mathrm{Pe}$ diatr. Res. 35:45-49.

54. O'Neill, W.C., and J.D. Klein. 1993. Regulation of vascular endothelial cell volume by Na-K-2Cl cotransport. Am. J. Physiol. 262:C436-444. 